\title{
The Approach to Safety of Children's Toys in United States and European Union: A Comparative Study
}

\author{
Rahmah Ismail $^{1}$ \\ Wan Amir Azlan Wan Haniff ${ }^{2}$ \\ Suzanna Mohamed Isa ${ }^{3}$ \\ Rozlinda Mohamed Fadzil ${ }^{4}$ \\ Syed Sagoff AlSagoff 5 \\ Kartini Aboo Talib @ Khalid ${ }^{6}$ \\ ${ }^{1}$ Associate Professor, Ph.D, Faculty of Law, National University of Malaysia, \\ 43600 UKM, Bangi, Selangor, Malaysia, \\ Corresponding Author \\ ${ }^{2}$ Ph.D Student, Faculty of Law, National University of Malaysia, \\ 43600 UKM, Bangi, Selangor, Malaysia, \\ ${ }^{3}$ Associate Professor, Ph.D, Faculty of Law, National University of Malaysia, \\ 4360o UKM, Bangi, Selangor, Malaysia \\ ${ }^{4}$ Senior Lecturer, Faculty of Law, National University of Malaysia, \\ 436oo UKM, Bangi, Selangor, Malaysia \\ ${ }^{5} \mathrm{Ph} . D$, Former Senior Officer, ASEAN Secretariat, Jakarta, Indonesia \\ ${ }^{6}$ Associate Professor, Ph.D, Institute of Ethnic Studies, National University of Malaysia, \\ 43600 UKM, Bangi, Selangor, Malaysia
}

Doi: 10.36941/ajis-2020-0o11

\section{Abstract}

Following the 'Year of Recall' in 2007 which saw greatest number of children's toys product recalls from United States of America (US) and European Union (EU) markets, both regions instituted new legislations governing children's products: the US Consumer Product Safety Improvement Act of 2008 (CPSIA 2008) and EU 2009 Toy Safety Directive. This article analyses the approaches to safety of toys adopted in US and EU in light of the potential for cross-jurisdictional use of the framework. This qualitative research utilizes secondary data gained from scientific database analysis and library research, including documents and precedents on toys safety. These data were analyzed by using legal interpretation and comparative assessment. The study finds key features of each jurisdiction as well as notable similarities and differences in terms of regulations, safety standards used such as International Organization for Standardization (ISO 8124); The American Society for Testing and Materials (ASTM F963); and European Standards (EN 71). Further, two competing systems, each with its own reigning global governor namely, Third-Party Assessor (3PA) supported by the US and Supplier's Declaration of Conformity System (SDOC) adopted by the EU, were assessed. When both systems were put into an evaluation, the extra third-party inspection for issuing certificate on the product based on 3 PA enable to provide important protection to consumers over the SDOC system. 


\section{Introduction}

United States of America (US) and European Union (EU) have always been the biggest importers of toy product in the world with China as their biggest supplier of toys. This could be proven when in 2017, from China alone, the former recorded approximately $85 \%$ of the US toy and game market, which equivalent to USD590.4 million imported value (Elizabeth, 2017), while the latter accounted for $86 \%$ of toy imports, which equivalent to almost $€ 6.364$ billion imported value (Eurostat, 2018).

However, the increase in number of toy product imports has led to the issue of toys safety for both regions. According to US Consumer Product Safety Commission (CPSC) Report (CPSC, 2017), in 2016 alone, an estimation of 174,100 toy-related emergency department-treated injuries and seven (7) deaths to children younger than 15 were recorded. Moreover, in 2017, US CPSC had issued 28 toy recalls and they were recalled for defects including choking, mechanical hazards and fire hazards that can injure a child (Kids in Danger, nd).

Still, the number of recalls is pale in comparison with the 'Year of Recall' in 2007, which saw the greatest number of children's toys product recalls from US and EU markets. Kids in Danger (2008) reported that there were total 448 recalls; with 231 total children's product recalls, or $52 \%$ of those were for children's products. From that number alone, almost half of it was due to excessive levels of lead in children's toys. World's renowned toy companies, Mattel Inc, has recalled 436,00o toy cars alone for violations of lead paint standards (European Commission, 2007; Story and Barboza, 2007). To add insult to the injury, the number of product recalls in fiscal year 2008 was even higher.

It is reported that painted plastic toys made of Polyvinyl chloride (PVC) materials have been major source of lead poisoning to children worldwide. Most common used material in manufacturing of soft plastic children toys are PVC materials. Lead compounds and cadmium are incorporated in PVC material so as to enhance its softness, stability, brightness and flexibility, hence making toys more attractive to children (Ghaly et al., 2013; Ismail et al., 2006; Livingstone et al., 2014; Yousif and Hasan, 2015).

Certainly, at high level of lead, it will cause many adverse clinical effects in consumers especially children. It can happen through oral contact when the children put the surface of toys product into their mouth, letting the lead contained within to be transferred into their biological system. Even if the product contains low dosage of lead, repeated action will put the health of the children to risk, which can pose danger to the reproductive organs, immune system, liver, kidneys and cardiovascular system (Bhagwat et al., 2008; Pratinidhi et al., 2014; Tong et al., 2000; Wani et al., 2015) as well as affects the development of the brain and nervous system when the harmful substance enters the blood stream (Shah et al. 2010; Mielke et al. 2010).

Apart from lead-based toys, phthalate also receive attention as well. Since 1997, public interest groups and regulatory agencies in Europe have expressed concern on the potential adverse health effects of phthalate. These 6 phthalates are di-(2-ethylhexyl) phthalate (DEHP), dibutyl phthalate (DBP), benzyl butyl phthalate (BBP), diisononyl phthalate (DINP), diisodecyl phthalate (DIDP) and n-octyl phthalate (DnOP) (Peter and Mate, 2009). According to Harrison (2010), phthalates or also known as plasticizers signifies to a group of chemical compounds that are heavily produced and widely used to make the plastics harder to break and more flexible. Linda and Margaret (2009) added that, over time, phthalates are released from those products and are dispersed to the water, soil, air and living things.

Swan (2008) believed that some of these phthalates are known to cause reproductive damage in rodents. While Kobrosly et al (2014) discovered that there is a relation between exposure of DBP and DEHP metabolites with behavioral problems in children, Braun et al (2013) and Zota et al (2014) pointed out that there is correlation between allergic diseases such as asthma and eczema with childhood exposure to DEHP and BBP. However, Chris and James (1999) argued that, based on the scientific evidence, the use of DINP in soft PVC toys and other children's products does not present a significant risk of adverse health effects in children.

Clearly, these recalls have made the global product safety standards that were initially ignored, 
are receiving public attention. Besides, most governments continuously updating their consumer product safety regulations to ensure the safety of children as consumers are protected, especially when they are at greater risk of hurting themselves than adults.

With the aim of analyzing the approaches to safety of toys adopted in US and EU in light of the potential for cross-jurisdictional use of the framework, the article first analyses toy safety regulations adopted in US and EU. Next, the paper examines on toy safety standards practiced by both regions and conformity assessment systems, which are Third-Party Assessor (3PA) supported by US and Supplier's Declaration of Conformity (SDOC) implemented by EU, for product safety determination for toys that are manufactured in China. This article will conclude by recommending the best model that could give best result for consumers and thus reducing the possibilities for unsafe products, especially children's toys to be available in the market. This qualitative research utilizes the secondary data gained from scientific database analysis and library research including documents and precedents on toys safety. These data were analyzed by legal interpretation and comparative assessment.

\section{Toy Safety Regulations in US and EU}

\subsection{Consumer Protection in US}

As an independent agency of US government, the CPSC was established in 1972 under Consumer Product Safety Act (CPSA). It emphases on safety of consumer products including children's toys (CPSC, nd). Since one of the objectives of CPSC is to investigate the causes and prevention of product-related deaths, illnesses, and injuries, the National Injury Surveillance System (NEISS) has been established and maintained by the CPSC to generate the statistic of the product-related injuries including children's toys from the hospital emergency departments (Section 5(a) (1) CPSA, 2008). Further, CPSC acts as a basis to formulate much preventative works on the consumer products (CPSC 2009-2015 Annual Report). Based on NEISS, CPSC (2017) reported that in 2016, there were an estimated 240,00o toy-related injuries treated in United States hospital emergency departments with seven (7) toy-associated deaths. In addition, as mentioned above, an estimated 174,100 cases happened to children younger than 15 years old (CPSC, 2017). It is important to note that although toys were associated with many of the incidents, those toys were not necessarily the cause of the deaths or injuries.

\subsection{Consumer Product Safety Improvement Act (CPSIA)}

The aftermath of 2007 recall has seen US to institute new legislations governing children's products especially those related to lead and phthalate content. In US, Consumer Product Safety Improvement Act 2008 (CPSIA 2008) was introduced by CPSC and became a national law in August 14, 2008 (S.L. Mak \& H.K Lau, 2017). The act wishes to address organizational and systemic deficiencies, as well as tackle specific consumer product defects and hazards such as those for lead content limit. The permissible amount limit of lead in children's toys product set by the US CPSC is up to 6oo parts per million (ppm) (US CPSC; Section 101(a) CPSIA 2008). Besides, the prohibition of phthalates in any children's toy or child care article that contains concentrations of more than o.1 percent of di-(2ethylhexyl) phthalate (DEHP), dibutyl phthalate (DBP), or benzyl butyl phthalate (BBP) also specified under section 108 CPSIA 2008. To ensure the compliance, a third-party testing for certain children's product by an independent third-party laboratory is mandatory and this applied to any children's product manufactured more than 90 days after the CPSC has established and published notice of the requirements for accreditation of third-party conformity assessment bodies (Section 102 CPSIA 2008).

The CPSIA 2008 also added a definition of children's product to the CPSA. Section 108(e) of the CPSIA 2008 defined children's product as a consumer product designed or intended primarily for children 12 years old or younger. 


\subsection{Consumer Protection in EU}

The principal law for consumer protection policy in EU was established pursuant to Article 38 of the Charter of Fundamental Rights of the EU (2000) and Articles 4(2)(f), 12, 114(3) and 169 Treaty on the Functioning of the EU (TFEU) (2012). Article 169 of the TFEU (2012) stated that:

"In order to promote the interests of consumers and to ensure a high level of consumer protection, the Union shall contribute to protecting the health, safety and economic interests of consumers, as well as to promoting their right to information, education and to organise themselves in order to safeguard their interests."

It is worth noting that the established key organisations such as the Directorate-General for Health and Food-Safety (DG SANTE) acting as an EU branch in driving consumer product safety matters both within Europe and internationally. Further, Directorate-General for Taxation and Customs Union (import safety) and Directorate-General for Enterprise and Industry (safety of regulated products) plays an important role in putting forward regulations aimed at further certifying the safety of products (Bowman, 2010). Nevertheless, Bowman (2010) added that DG SANTE has no jurisdictional authority and rights of inspection over EU Member States. Therefore, it is a duty for EU Member States authorities to verify general conformity of product standards by having the authorities to carry out appropriate sampling and safety test of manufactured products, follow-up on consumer complaints as well as reviewing product information file. Similar requirements are applied to imported products as well. It is worth to highlight that within the common market, the regulations apply to the manufacturer, importer, distributor and retailer (Bowman, 2010).

\subsection{EU Toy Safety Directive}

Normally, the General Product Safety Directive comes into play if no specific or sectorial (industry or product-specific) directive is available (Bowman, 2010). Toy product however, has its own directive. The original Toy Safety Directive 1988 (1988 Directive) was published in 1988. Following recent technological developments in toy industry, new issues have raised with regard to the safety of toys as more toys with new functions and materials were introduced to the market. Thus, it is clear that the 1988 Directive needs to be updated as well. Hence, the new EU Toy Safety Directive 2009 (2009 Directive) was introduced in 2009 to strengthen and update the rules on toy safety, especially in areas such as noise, chemicals, and choking hazards (UL, 2012). Once a Directive is published, all EU member-states must adopt it in their legislations (Negev, 2018).

Linda and Margaret (2009) stressed that there were requirements for EU Member States to take fundamental actions to conform to the standards described in the Directive. Besides, the Directive is binding instrument which compels them to carry out essential actions in bring their respective national laws into conformity with the essential requirements of the Directive, thus making the new Regulation as directly applicable and binding upon them. Linda and Margaret (2009) stated that:

"While the Directive is binding law on the Member States of the EU, requiring them to take necessary measures to bring their respective national laws into compliance with the Directive standards, the new Regulation is directly binding on the Member States. This means they are obligated to comply with the standard and enforce it without any implementing legislation or rule at the national level."

As a result, the 2009 Directive effectively integrates toy markets and toy safety regulations in EU and has become a legal document in all member states on 20 January 2011 (European Commission, nd.a). In United Kingdom for instance, the Toy Safety Directive was endorsed into domestic law. Toys (Safety) Regulations 1995 (1995 Regulations) and Toys (Safety) Regulations 2011 (2011 Regulations) were enacted pursuant to Section 11 of the Consumer Protection Act (1987). Both regulations were derived from European Directives (1998 Directive and Toy Safety Directive (2009)) respectively and 
was proposed to ensure businesses carry out safety conformity assessment of children's toys by certifying that their products are indeed safe. Besides, the 2011 Regulations which have superseded 1995 regulations place detailed obligations and prohibitions on parties in the supply chain to ensure toy safety and traceability from the manufacturer to consumers are accounted (Department for Business, Energy \& Industrial Strategy, 2012).

At this juncture, it is worth to highlight the definition of "safe" product. According to Article 2(b) General Product Safety Directive, safe product is:

"Any product which under normal or reasonably foreseeable conditions of use including duration and, where applicable, putting into service, installation and maintenance requirements does not present any risk or only the minimum risks compatible with the product's use."

Meanwhile, Article 2(c) General Product Safety Directive 2001 defines a dangerous product as any product that does not meet the definition of a safe product. Toys are regarded to be safe when they satisfy vital safety requirements as scheduled in the Annex of the Toy Safety Directive 2009. Once these toys meet the necessary minimum requirements as imposed, it will be affixed with a 'CE' mark and allowed to circulate within the internal market (Article 3(16), Toy Safety Directive 2009). Nonetheless, the 'CE' mark does not represent a guarantee of quality nor does it indicate prior approval of the toy. It merely shows that the manufacturer declared that it has applied all relevant EU Directives (European Commission, nd.b).

In the situation where the children's toys products did not comply with minimum safety requirement, the EU and its member states have the authorities to compel mandatory recalls (Article 42(1) Toy Safety Directive 2009), and companies or importers can negotiate voluntary recalls as necessary (Article 6(6)\&(7) Toy Safety Directive 2009). National authorities can alert consumers to the risks it presents, organize or order its actual and immediate withdrawal, coordinate or order its recall from consumers, ban the marketing of an unsafe product and organize its destruction in suitable conditions (Article 42(2), Toy Safety Directive, 2009). Plus, the businesses are under obligation to lodge report to the authorities if they sell hazardous children's toys products and if necessary, withdraw, stop and/or recall their distribution. In certain case, they need to abolish dangerous products from markets (Article 6 (7), Toy Safety Directive 2009).

Similar with CPSIA 2008, Njati \& Maguta (2019) pointed out that EU too modified 2009 Directive which resulted into new lead limit of $2.0 \mathrm{mg} / \mathrm{kg}, 0.5 \mathrm{mg} / \mathrm{kg}$ and $23 \mathrm{mg} / \mathrm{kg}$ for lead in dry, liquid and scraped-off toy material respectively. Currently, EU member states are now required to adopt the new lead limit levels into their respective national laws and regulations by 28 October 2018 (EU Council Directive, 2017).

\section{Toy Safety Standard in US and EU}

There are several safety standards available to assess safety of toys such as International Organization for Standardization (ISO 8124), The American Society for Testing and Materials (ASTM F963) and European Standards (EN 71). These standards are comparable in terms of their language but not their results. ASTM for example was established in 1898 and created the first toys safety standard in 1979 (ASTM International, nd). As a global testing standards organization, ASTM objectives are to publish testing standards to align with country standards and regulations like US and develop the material and product testing methods (ASTM International, nd). Prior 2008, ASTM F963 (Standard Consumer Safety Specification for Toy Safety) was a voluntary standard for toy manufacturers or importers, however, following the toys recall crisis in 2007, ASTM F963 were made mandatory under CPSIA (S.L. Mak \& H.K Lau, 2013). Currently, over 12,000 ASTM standards operate globally and the standards are applied in different industries such as toys and household products to increase the product safety (C. H. \& Lau, 2017).

Meanwhile, as for EU, there are two (2) standards that are used to assess the safety of toys, 
which are ISO 8124 and EN 71 . EN 71 are documents that have been ratified by one of the three European Standardization Organizations (ESOs), namely European Committee for Standardisation (CEN), European Telecommunications Standards Institute (ETSI) and European Committee for Electrotechnical Standardization (CENELEC). EN-71 is a set of European Product Safety Standards that applies to all toys sold in the EU (Cenelec, nd). All of these bodies have been recognized as competent in the area of voluntary technical standardization as for the EU Regulation 1025/2012 (Cenelec, nd).

EN-71 concerns toy safety issues with regards to mechanical and physical properties (EN-71-1), flammability (EN-71-2), specification for migration of certain elements (EN-71-3), experimental sets for chemistry and others goods related to it (EN-71-4), chemical toys (EN-71-5), graphical symbols for age warning labelling (EN-71-6), finger paints (EN-71-7), swings slides and similar activity toys for indoor and/or outdoor family domestic use (EN-71-8) and complex safety requirements (EN-71-9), such as sample preparation and extraction (EN-71-10) and methods of analysis (EN-71-11) (British Standards Institution, 2019).

As for ISO, the ISO is an independent, non-governmental membership organisation and has been recognised as the world's largest developer of voluntary international standards (ISO, nd). As of August 2019, ISO works in 164 different countries in the world (ISO, nd). Although it is not mandatory for EU to adopt such standard (Environmental technology, 2014), still, ISO have dedicated agreements with CEN and CENELEC to promote the benefits of the international standards to international trade and markets harmonization (CEN-CENELEC, nd).

The European Commission publishes harmonized standards for every Directive (Negev, 2018). For the purpose of children's toys, on 29 June 2013, the European Commission published a 'commission communication in the framework of the implementation of the 2009 Directive of the European Parliament and of the Council on the safety of toys' (Official Journal of the European Union, 2013). Thus, compliance with European standards provides presumption of conformity with requirements of 2009 Directive (TÜV SÜD, 2009).

This publication also has made standard such as specification for migration of certain elements (EN-71-3) which includes but not limited to phthalate and lead, into harmonised standards. Similar with the requirement under CPSIA, EU also have harmonized requirements regarding phthalates in toys, with each banning three types of phthalate contain more than $0.1 \%$ of DEHP, DBP, or BBP (Commission Regulation (EC) No 552/2009). A similar ban also apply to the remaining three (3) phthalates in toys that could be put in a small child's mouth (European Commission, 2009, 2013). However, despite the banning, the accused who has been charged under phthalate offence may defence himself by using due diligence defence as long he can prove that he exercised reasonable precautions to avoid the commission of the offence by himself or any person under his control.

\section{Toy Safety and Conformity Assessment in EU and US}

Before examining the effect of the two competing systems for conformity assessment, it is worth to highlight first about the definition of conformity assessment. As defined by the ISO (nd), conformity assessment is a set of processes that demonstrate the compliance of a product, service, or system with the requirements of applicable manufacturing standards. The system implemented by US is ThirdParty Assessor (3PA), while EU adopts Supplier's Declaration of Conformity System (SDOC), each with its own reigning global governor.

Section 102 of the CPSIA amends CPSA §14 (codified at 15 U.S.C. §2063) which requires manufacturer (including an importer) of a toy or children's product designed or intended primarily for children aged 12 and younger to have its product tested by accredited third-party laboratories. Since children's toys are required by law to meet certain standards, CPSC creates an accreditation program that 
allows laboratories and testing facilities to meet the requisite standards and the testing laboratory must issue a certificate that the product meets all applicable CPSC requirements (S.L. Mak \& H.K Lau, 2016). If the laboratory is immensely influenced by a manufacturer or government entity, or failed to meet the requirement established by CPSC, the CPSC is authorized to revoke accreditation (Section 102 CPSIA 2008; Peter and Mate, 2009).

However, Johnson (2008) and the National Research Council (2009) highlighted that unlike EU SDOC system, ${ }_{3} \mathrm{PA}$ has been postulated as a technical barrier to trade due to the fact that ${ }_{3} \mathrm{PA}$ entails suppliers to pay for independent testing. Defenders argue that it is necessary as the system is primarily designed to ensure greater protection to consumers by offering liability protection to retailers and manufacturers as well as removing conflicts of interest. (National Research Council, 1995).

\subsection{Supplier's Declaration of Conformity System (SDOC)}

SDOC is the procedure by which a first party or supplier (e.g. manufacturer, importer, distributor or assembler) provides written assurance that the object of conformity fulfills the applicable standards and technical regulations of the importing country (Derek \& Sara, 2018). While 3 PA is preferred conformity assessment system by the US, EU adopts SDOC system. Under SDOC system, importing country needs to conduct domestic post-market surveillance that comprises tests of products reported by suppliers or consumers as potentially unsafe (Derek \& Sara, 2018). However, Nationally Recognized Testing Laboratory (2008) stressed the weakness of this system could be seen when there is an inconsistent testing capability as the testing differs from country to another. Nevertheless, Derek \& Sara (2018) believed that by delegating conformity assessment responsibilities to the supplier, the cost of entry for exporting suppliers can be reduced since the supplier does not need to have products to be externally tested.

SDOC and ${ }_{3}$ PA conformity assessment systems acts as hindrance of products with safety issues to enter into market. Still, some of unsafe products are successfully reached into the market. Recall process comes into picture as it removes products with known hazards from the hands of consumers, in which, lower rate of recall indicates much proactive action in terms of providing safer consumer environment, while the higher recall numbers reflect a significantly higher total number of dangerous products that are compulsory to be withdrawn from consumer reach. This means, more people were exposed to the risks that are posed by products, which are not fulfilling global safety standard.

Research has been done by Derek and Sara (2018) to examine the development and effect of these two competing systems. To ensure the differences in terms of geographical, historical as well as trade agreement distinctions in the trade patterns between both jurisdictions be minimized, only children's toys that were manufactured in China being inspected. In order to track these recalls, EU Rapid Alert System (RAPEX) and US CPSC SaferProducts.gov portal were used to gather data on the product recall information. These are the state regulatory agencies in which each recall that has been announced must be reported to the applicable authority, subsequently makes the information publicly available.

When both systems were put into an evaluation, it shows that the EU model, SDOC, exposed a higher number of recalls of products in the market with ten times more compared to the US model, ${ }_{3} \mathrm{PA}$, within the span of five years (Derek \& Sara, 2018). This proves that the extra third-party inspection for issuing certificate on the product based on the $3 \mathrm{PA}$ enable to provide important protection to consumers over the SDOC system. In addition, the advantages of ${ }_{3} \mathrm{PA}$ system were prevalent in terms of safety within toy products categories as it is not limited only to the aggregate level for the consistently lesser total recalls, but also within all hazard categories.

The most eminent factor of toy recalls in EU related to chemical hazards is breach in phthalate standard, staggeringly responsible for 8o-93 percent of total recalls (Derek \& Sara, 2018). In fact, there is no corresponding decrease recorded for phthalate-based recalls in EU (Derek \& Sara, 2018). Contrary to US, toy recalls due to chemical hazards declined since companies adjusted to much 
stricter lead content limitation standards in parallel with CPSIA requirement. As a result, there was only one recall for the same CPSC's phthalate debarment (Derek \& Sara, 2018). When it comes to the implementation of regulations, it is noteworthy that CPSC and US Customs and Border Protection were dedicated to the task and this is shown in the fiscal year of 2017 when more than 745,00o toys were seized at the ports for breaching toy standards with almost half of them are toys with excessive lead content. These violative products were prohibited from entering US and never made it onto store shelves (The Toy Association, 2017).

\section{Conclusion}

Children's toys market is constantly developing due to consumer demands and technological advancements. Meaning, more toys will be produced and hidden hazards that comes with it is inevitable. It is observed from NEISS statistic, the number of toys-related death and injuries cases is alarming despite there has been a lot of effort among authorities to enhance the product safety in the past years. Undeniably, harmonized regulatory standards able to create appearance of single regulatory structure and ${ }_{3} \mathrm{PA}$ model could be applied as the best model compared to SDOC. Nevertheless, as discussed above, the execution of global rules is not uniform, thus, crucial dangers to consumer safety is still presence. Clearly, tireless effort from regulatory committees to improve the toys safety standards and regulations, as well as implementation of such regulations, are needed.

\section{Acknowledgment}

This article is part of the findings of Fundamental Research Grant Scheme (FRGS/1/2017/SSI1o/UKM/o2/4) entitled Toy Safety: A Development of Toy Safety Policy in ASEAN, funded by the Ministry of Education Malaysia.

\section{References}

ASTM International. (nd). ASTM International's World-Renowned Toy Safety Standard (F963). Retrieved from https://www.astm.org/toys.html

Bhagwat, V.R., Patil, A.J., Patil, J.A. and Sontakke, A.V. (2008). Occupational lead exposure and liver functions in battery manufacture workers around Kolhapur (Maharashtra). Al Ameen J Med Sci. 1(1), 2-9.

Bowman, I. E. (2010). Consumer Product Safety Commission issues. New York: Nova Science.

Braun, J.M., Sathyanarayana, S., Hauser, R., (2013). Phthalate exposure and children's health. Curr Opin Pediatr. 25 (2), 247.

British Standards Institution. (2019). Multi-part document BS EN 71- Safety of toys. Retrieved from https://landingpage.bsigroup.com/LandingPage/Series?UPI=BS\%2oEN\%2071

CEN-CENELEC. (nd). ISO \& IEC. Retrieved from https://www.cencenelec.eu/intcoop/StandardizationOrg /Pages/default.aspx

CENELEC. (nd). What is a European Standard (EN)? Retrieved from https://www.cencenelec.eu/standards/DefEN /Pages/default.aspx

C. H., \& Lau, H. K. (2017). A critical review of product safety in industry 4.0 applications. 2017 IEEE International Conference on Industrial Engineering and Engineering Management (IEEM). doi:10.1109/ieem.2017.8290175

Chris, F.W.,\& James, C, L. (1999). The Potential Health Effects of Phthalate Esters in Children's Toys: A Review and Risk Assessment. Regulatory Toxicology and Pharmacology,30 (2), 140-155. doi: 10.1006/rtph.1999.1338

Consumer Product Safety Improvement Act 2008 (United States).

Consumer Protection Act 1987 (United States).

CPSC. (2017). Toy related-deaths and injuries calendar year 2016. Retrieved from https://cpsc.gov/s3fspublic/Toy_Report_2016.pdf?6ZwpKyiwsEdVzWXhHomodoo5cJALIZFW

CPSC 2009-2015 Annual Report. Retrieved from https://www.cpsc.gov/About-CPSC/AgencyReports/AnnualReports 
Department for Business, Energy \& Industrial Strategy. (2012). Toy manufacturers, importers and distributors: your responsibilities. Retrieved from https://www.gov.uk/guidance/toy-manufacturers-and-theirresponsibilities\#introduction

Derek, B.L \& Sara, R.J. 2018. Playing it safe: toy safety and conformity assessment in Europe and the United States. International Review of Administrative Sciences. o(o):1-17.

Elizabeth. (2017, December 1). A toy story of U.S. imports. More Than Shopping. Retrieved from https://www.morethanshipping.com/toy-story-u-s-imports/

EU Council Directive. (2017). Council Directive 2017/738 of 27 March 2017 amending, for the 820 purpose of adapting to technical progress, Annex II to Directive 2009/48/EC of the European 821 Parliament and of the Council on the safety of toys, as regards lead. Official Journal of the 822 European Union, L 110/6, p.1.

Environment Technology. (2014). Understanding European (CEN) and International (ISO) standards. Retrieved from https:/www.envirotech-online.com/article/air-monitoring/6/source-testing-association/understandingeuropean-cen-and-international-iso-standards/1765

European Commission (2007) Consumers: Mattel expands recall of Chinese toys. 16 August. Available at: http://europa.eu/rapid/press-release_IP-o7-1234_en.htm?locale1/4en

European Commission. (nd.a). Toy Safety in the EU. Retrieved from https://ec.europa.eu/growth/sectors /toys/safety_en

European Commission. (nd.b). Official Portal of European Commission. Retrieved from https://ec.europa.eu/growth/single-market/ce-marking_en

European Commission. (2009). Toy Safety Directive 2009, 2009/48/EC, per Annex I to Directive 76/769/EEC.

European Commission. (2013). Enterprise and Industry Directorate (2013) Toy Safety Directive 2009/48/EC: An Explanatory Guidance Document. Retrieved from file://Users/User/Downloads/tsd-rev1-7-explanatoryguidance-document-en\%2o(1).pdf

Eurostat. (2018, December 22). Where do our toys come from?. Eurostat. Retrieved from https://ec.europa.eu/eurostat/web/products-eurostat-news/-/DDN-20181222-1

General Product Safety Directive. 2001/95/EC.

Ghaly, W., Mohsen, H., Rashad, A. and Helal, A. (2013). Elemental Composition of some Imported Toys and Handbags by X-ray Techniques. Journal of American Science. 9(7), 476-479.

Harrison, P. (2010, October 18). Special Report: The problem with phthalates. Reuters. Retrieved from https://www.reuters.com/article/us-plastics-health/special-report-the-problem-with-phthalatesidUSTRE69H1PM20101018

Ismail, S.N.S., Mohamad, N.S., Karmegam Karuppiah, Abidin, E.Z., Rasdi, I. and Praveena, S.M. (20o6). Heavy metals contents in low-priced toys. ARPN Journal of Engineering and Applied Sciences, 12(5), 1499-1509.

ISO. nd. About ISO. Retrieved from https://www.iso.org/about-us.html

ISO 8124-1.(2018) Safety of Toys -- Part 1: Safety aspects related to mechanical and physical properties. Retrieved from https://www.iso.org/standard/74477.html

ISO 8124-2. (2014). Safety of toys: Part 2: Flammability. Retrieved from https://www.iso.org/standard/59695.html

ISO 8124-3. (2010). Safety of toys: Part 3: Migration of certain elements. Retrieved from https://www.iso.org/standard/43471.html

ISO 8124-6. (2018). Safety of toys -- Part 6: Certain phthalate esters in toys and children's products. Retrieved from https://www.iso.org/standard/70oo8.html

ISO 8124-4. (2014). Safety of toys: Part 4: Swings, slides and similar activity toys for indoor and outdoor family domestic use. Retrieved from_https://www.iso.org/standard/66627.html

Johnson C. (2008). Technical Barriers to Trade: Reducing the Impact of Conformity Assessment Measures. Office of Industries Working Paper, United States International Trade Commission (September).

Kids in Danger. (2008). 2007: The Year of the Recall. Retrieved from https://www.kidsindanger.org/docs/reports/2008_year_of_the_recall.pdf

Kids in Danger. (nd). Product hazard - Toys. Retrieved from https://kidsindanger.org/product-hazards/toys/

Kobrosly, R.W et al., (2014). Prenatal phthalate exposures and neurobehavioral development scores in boys and girls at 6-10 years of age. Environmental Health Perspectives. 122 (5), 521.doi: 10.1289/ehp.1307063

Linda, S., \& Margaret, L,. M. (2009). Phthalates in plastics and possible human health effects. In Peter A. Varga \& Mate Pinter. Consumer Product Safety Issues (pp. 231-250). New York: Nova Science.

Livingstone, K.G., Leticia, B. and Emmanuel, O. (2014). Assessment of Level of Lead and Cadmium in Selected Plastic Toys Imported from China on the Ghanaian Market, Chemistry and Materials Research, 6 (1), $62-68$.

Mielke HW, Laidlaw MAS, Gonzales C. (2010) Lead ( $\mathrm{Pb}$ ) legacy from vehicle trafic in eight California urbanized areas: continuing infuence of lead dust on children's health. Sci Total Environ, 408(19):3695-3975. https://doi.org/10.1016/j.scito tenv.2010.05.017 
National Research Council (NRC). (2009). Science and Decisions: Advancing Risk Assessment. Washington, DC: National Academy Press.

National Research Council (NRC). (1995). Standards, Conformity Assessment, and Trade into the 21st Century. Washington, DC: National Academy Press.

Negev, M., et al. (2018). Regulation of Chemicals in Children's Products: How Us and Eu Regulation Impacts Small Markets. Science of the Total Environment, 616-617, 462-471. doi: 10.1016/j.scitotenv.2017.10.198

Njati, S. Y. \& Maguta, M. M. (2019). Lead-Based Paints and Children's Pvc Toys Are Potential Sources of Domestic Lead Poisoning. Environmental Pollution. 249:1091-1105. doi: 10.1016/j.envpol.2019.03.062

NRTL (Nationally Recognized Testing Laboratories) (2008) Supplier's Declaration of Conformity, Product Safety in an SDOC System. Retrieved from https://www.federalregister.gov/articles/2008/10/20/E824826/nationally-recognized-testing-laboratoriessuppliers-declaration-of-conformity\#h-15

Pratinidhi, S.A., Patil, A.J., Behera, M., Patil, M., Ghadage, D.P. and Pratinidhi, A.K. (2014). Effects of blood lead level on biochemical and hematological parameters in children with neurological diseases of Western Maharashtra, India. J Basic Clin Physiol Pharmacol. 25(2), 229- 1020 233. doi: http://dx.doi.org/10.1515/jbcpp2013-0062.

Shah F, Kazi TG, Afridi HI, Baig JA, Khan S, Kolachi NF et al. (2010). Environmental exposure of lead and iron defcit anemia in children age ranged 1-5 years: a cross sectional study. Sci Total Environ, 408(22):5325-5330. doi: 10.1016/j.scitotenv.2010.07.091.

S. L. Mak \& H. K Lau. (2013). A Study on the Toy Safety Assessment Model. Retrieved from https://www.researchgate.net/publication/269326567_A_study_on_the_toy_safety_assessment_model.

Story L and Barboza D. (2007, August 15). Mattel recalls 19 million toys sent from China. The New York Times. Retrieved from http://www.nytimes.com/2007/08/15/business/worldbusiness/15imports.html

Swan, S. H. (2008). Environmental phthalate exposure in relation to reproductive outcomes and other health endpoints in humans. Environmental Research. 108(2), 177-184.

The Toy Association. (2017, November 17). CPSC Issues Reminder on Toy Safety; Releases Statistics on Injuries, Product Seizures, \& Recalls. The Toy Association. Retrieved from https://www.toyassociation.org/PressRoom2/News/2017_News/cpsc-issues-reminder-on-toy-safetyreleases-statistics-on-injuries-product-seizures-recalls.aspx

TÜV SÜD (2013, July). EU new harmonised standards under toy safety directive. TÜV SÜD. Retrieved from https://www.tuv-sud.com/home-com/resource-centre/publications/e-ssentials-newsletter/consumerproducts-e-ssentials/consumer-products-e-ssentials-vol.-73/eu-new-harmonised-standards-under-toysafety-directive

Tong, S., Schirnding, Y.E.V. and Prapamontol, T. (2000). Environmental lead exposure: a public health problem of global dimensions. Bull World Health Organ, 78(9), 1068-1077. doi: 10.159o/Soo42-96862000000900003

Toy Safety Directive 1988. 88/378/EEC.

Toy Safety Directive 2009. 2009/48/EC.

Toys (Safety) Regulations (1995).

Toys (Safety) Regulations (2011).

Treaty on the Functioning of the European Union. 2012/C.

UL. (2012, August 2). Reference Guide EU Toy Safety Directive 2009/48/EC. Retrieved from https://www.ul.com/global/documents/verificationservices/businesssegments/Consumer/English/EU\%2oT oy\%2oSafety\%2oDirective\%2oReference\%2oG uide\%2o(form).pdf

Wani, A.L., Ara, A. and Usmani, J.A. (2015). Lead toxicity: a review. Interdisciplinary toxicology, 8(2), 55-64. doi: http://dx.doi.org/10.1515/intox-2015-0oog.

Yousif, E. and Hasan, A. (2015). Photostabilization of poly(vinyl chloride) - Still on the run. JTUSci, 9(4), 421-448. doi: http://dx.doi.org/10.1016/j.jtusci.2014.09.007.

Zota, A.R., Calafat, A.M., Woodruff, T.J. (2014). Temporal trends in phthalate exposures: findings from the national health and nutrition examination survey, 2001-2010. Environmental Health Perspectives, 122 (3), 235241. doi: 10.1289/ehp.1306681 